\title{
Evaluation of the Profitability of Listed Companies A Case Study of Guizhou University of Finance and Economics
}

\section{Kewen Zhang}

Guizhou University of Finance and Economics, Guiyang, 550025, China

\begin{abstract}
Under the influence of the gradual rise and development of Internet Banking, there are many kinds of lending platform for college students in market. These platforms are uneven that let users face a series of unknown risks. Facing this special group of college students, the risk of loan business is inevitable. Whether lending platform, financial regulation or government management should actively cope with risks. This paper takes Guizhou finance and economics university as the research object, and through the questionnaire survey to understand the college students' loan demand and market supply. In order to fully analyze the causes of College Students' consumption credit, the author puts forward the countermeasures from several aspects, so as to achieve control of the college students' loan risk.
\end{abstract}

\section{Keywords}

College student; Risk; Peer-to-peer Leading; Risk Management

\section{大学生借贷风险及控制一以贵州财经大学为例}

\author{
张克雯 \\ 贵州财经大学, 贵阳 550025, 中国
}

摘要：在逐步兴起与发展互联网金融的影响下，市场上专门针对大学生的网络借贷平台也是 五花八门。这些借贷平台参差不齐, 让使用者面临一系列的未知的风险, 面对大学生这一特 殊群体，借贷业务的风险是不可避免的，不管是借贷平台、金融监管还是政府的管理都应该 积极应对风险，本论文以贵州财经大学为研究对象并通过问卷调查的形式来了解大学生借贷 需求与市场供给状况，以此充分分析大学生消费信贷的风险成因，从多个方面来提出应对对 策，从而达到对大学生借贷风险的控制。

关键词: 大学生; 风险; 网络借贷; 风险控制 


\section{1. 引言}

随着互联网技术的发展，人们的 消费习惯正在发生改变, 大学生是年 轻群体对新生事物接受较快, 互联网 金融也针对大学生提供许多网络借贷 的平台, 但是这也给大学生的经济安 全带来隐患，比如网络诈骗、法律监 管缺陷、业务范围不清楚等, 大学生 的应对能力与经验相对缺少，可能会 对其本身造成泄露信息、被欺诈等问 题。目前, 各种商业平台也逐渐把目 光转向大学生, 使一种集分期借贷消 费与贷款于一身的网络借贷平台应运 而生, 而这些网络借贷平台鱼龙混 杂。近段时间, 大学生由于负担不了 高额的利息和本金而自杀的事件频 发, 引发公众的讨论和关注。在众多 的问题后面我们不禁思考, 大学生借 贷问题频发源自大学生自身的风险防 范的意识不够、金融机构监管的不利 还是政府管理的不足等问题，所以， 对大学生借贷风险成因及对策的研究 势在必行。

\section{2. 大学生借贷需求分析}

基于大学生借贷需求情况分析的 需要, 对贵州财经大学在校大学生发 放 “大学生借贷需求调查问卷”, 本 次问卷调查发放问卷 500 份，收回 489 份，没有无效问卷，接受问卷调查的 男女生比例基本持平，一、二、三、 四年级比例基本均等, 涉及大部分专 业。现将问卷调查结果分析如下:

\section{1. 借贷需求普遍存在}

通过对问卷调查结果进行分析, 结果表明贵州财经大学在校大学生的 借贷需求普遍存在。从问题 “你在大 学期间是否有过借贷需求?”的调查 结果显示, 回答有的学生占参与问卷
调查总数的 $67 \%$, 而回答没有的学生 只占参与问卷调查总数的 $33 \%$ 。这一 结果表明, 很大部分大学生是存在借 贷需求的。

针对上述的问题, 究其原因, 在 之后的问题 “您的借贷需求是为了应 对?”的调查结果显示 $26 \%$ 的学生选 择 “生活费超支”; $21 \%$ 的学生选择 “用于购买高档电子产品、化妆品 等”； 37\% 的学生选择了 “其他”, 其 中大致概括为: 送女朋友礼物、临时 救急等为了应对突发或者不经常发生 的事件。

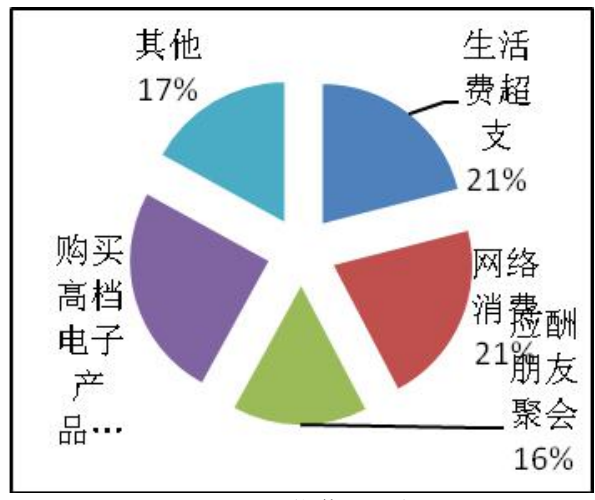

图 1：借贷用途

通过以上两个问题的调查结果来 看, 大学生由于缺乏理财经验, 以及 消费观念存在超前的观念等原因, 贵 州财经大学在校大学生的借贷需求较 高, 且大多为消费目的。由此可以说 明, 在校大学生的借贷需求旺盛, 是 近年来大学生借贷市场比较繁荣的主 要原因。

\section{2. 借贷需求通过网络借贷平台实现}

在本次问卷调查结果显示, 当大 学生存在借贷需求后, $40 \%$ 的大学生选 择使用花呗、京东白条等电商自带的 分期产品; $36 \%$ 的大学生选择找朋友 借; 还有 $16 \%$ 的大学生选择其他, 概 括为会选择分期乐等独立的分期网络 借贷软件, 或者会选择多种方式进行 
借贷; 而选择使用借贷宝等 P2P网络 借贷软件只占 $5 \%$; 选择使用信用卡进 行透支的大学生仅仅占总数的 $3 \%$ 。对 以上的结果分析, 由于大学生的借贷 需求多发生于网络购物, 所以大部分 大学生会选择电商提供的分期借贷产 品, 其次找朋友借钱的占比也较大。

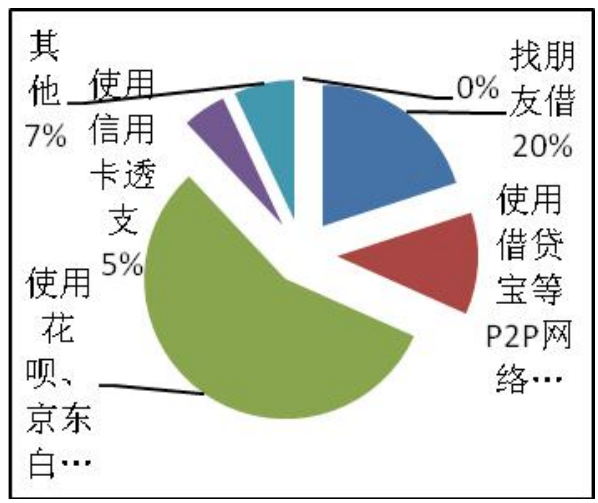

图 2: 借贷途径

\section{3. 大学生借贷方式选择特点}

在此次调查中, 针对借贷平台选 择原因的调查结果显示, 手续简单这 一原因以 $72 \%$ 的高选择率为大学生借 贷方式的首选的主要原因; 认为贷款 利率低的选择为 $32 \%$; 放款快这一原 因的选择占比 $34 \%$; 贷款机构可信度 的选择率为 $24 \%$; 其他的选择为 $26 \%$ 。大学生借贷线上供给是指在校大 学生通过网络平台来实现借贷, 其中 包括分期平台, $\mathrm{P} 2 \mathrm{P}$ 平台等。在 “最常 使用的分期平台” 问题的调查结果 中, 我们可以看到分期乐占比 $36 \%$, 爱又米占比 $35 \%$, 两家平台借贷额度 占据大部分市场份额。随后是蚂蚁花 呗占据 $18 \%$ 、京东白条占据 $8 \%$ 的市场 份额, 而其他平台的占比均不大。有 需求就有市场, 大学生分期消费的需 求量还在持续上涨, 这给分期平台商 提供了很大的机遇, 所以在以后的分 期服务上将会出现更为丰富的形式。
通过以上数据的分析, 可知贵州 财经大学在校大学生在选择借贷方式 时, 手续简单是首选考虑的条件, 其 次为放款快和利率低也是选择的重要 方面。在对贷款机构可信度上来说相 对选择较低, 在调查中仅仅占 $24 \%$ 。 虽然时间短、效率高、利息率低是大 学生借贷选择的主要参考因素, 但是 最重要的安全性却没能得到借贷大学 生的重视, 这也体现了大学生借贷时 安全意识较差, 这也使得大学生在借 贷时的风险大幅度提高。

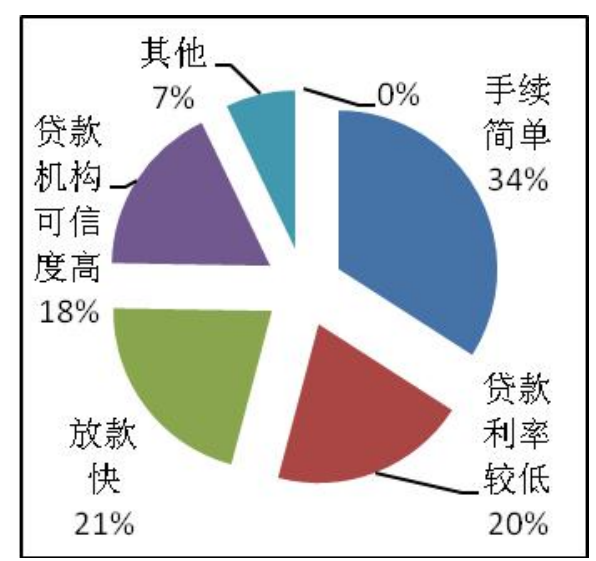

图 3: 选择原因

\section{3. 大学生借贷供给分析}

\section{1. 线上供给}

大学生借贷线上供给是指在校大 学生通过网络平台来实现借贷, 其中 包括分期平台, $\mathrm{P} 2 \mathrm{P}$ 平台等。在 “最常 使用的分期平台” 问题的调查结果 中, 我们可以看到分期乐占比 $36 \%$, 爱又米占比 $35 \%$, 两家平台借贷额度 占据大部分市场份额。随后是蚂蚁花 呗占据 $18 \%$ 、京东白条占据 $8 \%$ 的市场 份额, 而其他平台的占比均不大。有 需求就有市场, 大学生分期消费的需 求量还在持续上涨, 这给分期平台商 提供了很大的机遇, 所以在以后的分 期服务上将会出现更为丰富的形式。 


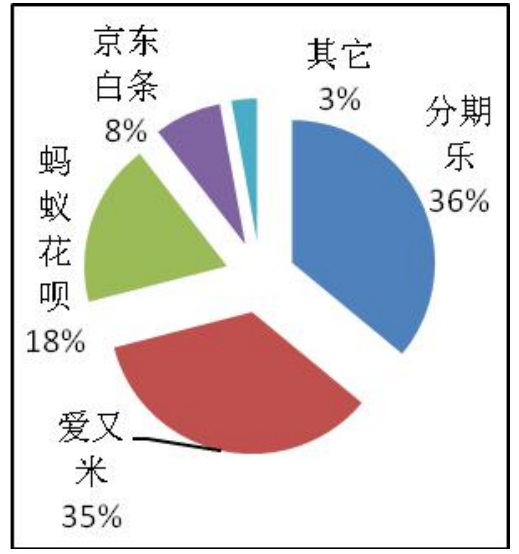

图 4: 使用占比

\section{2. 线下供给}

大学生借贷线下供给主要是指当 大学生存在借贷需求后, 通过银行等 非网络渠道的方式来进行借贷。目 前, 大学生的借贷方式主要包含大学 生助学贷款 (通常分为两类:国家助学 贷款和生源地信用助学贷款）、大学 生创业贷款、消费贷款三大类，线下 借贷的方式相对网络借贷具有手续繁 杂、借贷金额较大等特点, 不适用于 广大在校生消费借贷的需求特点。

\section{4. 大学生借贷风险}

\section{1. 法律风险}

虽然大学生的素质和受教育程度 相对较高, 但是金融和法律知识储备 却不足, 根据法律的相关规定: 双方 约定的利率未超过年利率 $24 \%$, 出借 人请求借款人按照约定的利率支付利 息的，人民法院应给予支持。年利率 超过 36\%的就为高利贷，而年利率在 24\%-36\% 的就属于法律的空白, 这部 分是无法受到相关约束的。在实际生 活中, 很少有大学生意识到这一点, 由于法律意识的缺乏, 导致一些不合 理的借贷平台 “乘虚而入”，法律及
金融相关知识的缺乏, 是导致大学生 借贷风险的根本成因。

\section{2. 信息安全风险}

据了解, 学生如果申请了分期贷 款, 借贷平台的线下工作人员会到宿 舍走访, 确认包括学生证、身份证、 饭卡、成绩单和家庭住址、父母的联 系方式等信息; 审核通过后, 学生要 签合同, 按手印, 再拍照录入系统, 而如果逾期还款超过一定期限, 借款 学生的个人信息和购物需求在平台上 有详细披露。但是, 这些信息一旦被 信贷公司取得, 其安全性很难得到有 效保障, 存在很大的信息泄露隐患。 而许多网络借贷平台借贷手续没有银 行借贷的要求严格, 并不需要本人到 现场办理业务, 导致很多学生的由于 信息泄露而背上巨额债务, 这将给大 学生造成很大的风险隐患。

\section{3. 信用风险}

若大学生贷款时由于可能会因信 息不对称等问题, 导致无法正常还款 从而影响个人征信。学生贷款之后, 面对较大金额的还款本金及利息费 用, 常常束手无策, 从而发生逾期还 款行为。但许多互联网信贷平台是与 银行合作的, 如果不还款, 会影响到 贷款学生的终生征信, 而信用记录一 旦出现污点, 那么以后向银行申请贷 款、信用卡都会受到非常严重的影 响。

\section{5. 大学生借贷风险对策}

\section{1. 完善法律、加强监管}

目前, 我国关于应对大学生网络 借贷的相关法规还十分薄弱, 对于网 络借贷的硬性规定也较少, 能够对其 约束的只有《民法通则》和《合同 法》中有规定的条款, 由此就造成了 
法律监管的空白地带。而大学生借贷 行为具有很多的特殊性, 监管就显得 很力不从心, 导致近期大学生的借贷 问题频发。所以政府应该加快完善相 关法律法规体系建设, 加强监管力 度, 例如建立市场准入的具体标准、 专业的平台风险考核制度、加强相关 信息披露等, 多管齐下, 从根本上保 障大学生借贷安全。

\section{2. 加强借贷平台建设}

从以上的风险分析可知, 借贷平 台安全对技术的要求十分高, 容不得 一点马虎。所以, 从借贷平台来说, 提高平台安全技术管理是对借贷用户 的负责任的体现。一是, 可以通过加 强专业技术维护人员的培训和相关人 才的引进, 为平台安全平稳运营提供 技术支持; 二是, 可以提高信息系统 的维护和提高安全指数, 从而达到保 障用户使用的安全。

另外, 借贷平台应完善大学生信 用评级及风控机制, 着力提高风险控 制能力, 建立信用预警机制及失信惩 戒机制、建立风险评估模型, 将风险 划分等级进行监督管理。同时, 校园 信贷业务的提供机构不能唯利是图, 在追求企业经济利润的同时更应该担 负起自己的社会责任。

\section{3. 加强大学生消费、理财的引导教育}

一方面, 大学生自身应加强诚信 意识及理财技能, 树立正确的消费 观。大学时代作为培养理财能力的黄 金时期, 大学生应主动学习理财知 识, 充分利用我校诸如模拟炒股大 赛、金融投资俱乐部等各类比赛、社 团平台, 逐步提高自己的理财规划能 力。

另一方面, 学校应加强学生诚 信、风险意识和法律教育, 如贵州财 经大学金融学院, 就对其所有专业开
设了特色课程《诚信学》, 加强学生 诚信意识, 引导大学生养成良好的消 费、理财、信贷习惯以及今后遵守职 业操守。

同时, 家庭教育应注重培养子女 合理的消费习惯与理财意识, 及时掌 握子女的消费心理与消费动态, 以便 及时教育, 不断地探索新的教育方 法, 使得家庭教育能够与时俱进, 做 到在日常生活中及时发现问题解决问 题。

\section{致谢}

本文来源于 2016 年度贵州财经大 学引进人才科研项目《互联网金融与 传统金融模式的冲突与融合研究》, 项目号：2016YJ06。

\section{参考文献}

[1] 陈鹏. 消费价值观对大学生信用消 费影响的实证分析 $[\mathrm{J}]$. 技术与创新 管理,2013,34(04):397-400+410.

[2] 袭爱娥, 鲁菁, 刘小亮. 90 后大学 生分期消费状况巧析机 [J]. 科技创 业月刊，2016.1.

[3] 王永峰.大学生分期市场成长与问题 巧析[J]. 科技经济市场，2016.01.

[4] 本报记者程墨 实习生 张闻 曹栗. 警惕高利贷潜入校园[N]. 中国教育 报,2008-04-04(001).

[5] Freedman S, Jin G Z. Learning by Doing with Asymmetric Information:evidence from Prosper.com [R]. National Bureau of Economic Research, 2011: 1-40. 